\title{
Effects of Anaerobic Training on Paraoxonase-1 Enzyme (PON1) Activities of High Density Lipoprotein Subgroups and Its Relationship with PON1-Q192R Phenotype
}

\author{
Faruk Turgay ${ }^{1}$, Ali Rıza Şişman² and Aylin Çeçen Aksu ${ }^{3}$ \\ ${ }^{1}$ Ege University School of PhysicalEducation and Sport, Department of Sport Health Sciences, Bornova-Izmir, Turkey \\ ${ }^{2}$ Dokuz Eylul University, Medical Faculty, Biochemistry Department, Izmir, Turkey \\ ${ }^{3}$ Sports Medicine Private Practice, özel Sağlık LTD. ŞTI, Izmir, Turkey
}

\begin{abstract}
Aim: Paraoxonase-1 (PON1) is an antiatherosclerotic enzyme located on high-density lipoprotein (HDL). The effects of anaerobic exercise on PON1 activity are unknown. Here we investigated the effects of anaerobic judo training on three different activities of same PON1 enzyme (TDPON1), including basal PON1, salt-stimulated PON1 (SPON1), and arylesterase (AE) activities, of serum, HDL, and HDL subgroups (HDLs; HDL and its subgroups) and its relationship with PON1-Q192R phenotype (PON1P).

Methods: Our study included 18 Turkish national female judoists (mean age: $17.9 \pm 0.8$ years). Before and after 5 months of anaerobic training, critical speed (CS), TDPON1 activities, cholesterol levels in the serum and supernatants of HDLs obtained by polyethylene glycol, and other major blood lipids and lipoproteins (BLLPs) including triglycerides were determined using blood samples taken after overnight fasting. PON1P groups (PGs) were categorized as QQ (QG; persons with low activity) and $\mathrm{R}$ carriers $(\mathrm{QR}+\mathrm{RR}$ ) (RG; persons with high activity) according to SPON1/AE activity ratios. The results were considered statistically significant at $P \leq 0.05$.

Results: Anaerobic training resulted in significantly increased the cholesterol levels of HDLs (except $\mathrm{HDL}_{2}-\mathrm{C}$ ) in all subjects, but not HDLs-C in PGs. Anaerobic training resulted in significant increases in most TDPON1 activities of serum and HDLs in all subjects and (except AE) in PGs, whereas SPON1 and $\mathrm{HDL}_{2} \mathrm{AE}$ activities increased only in the RG, which was related to PON1P. However, PON1P was not related to other measured markers, including basal BLLP profiles.

Conclusions: Anaerobic training improved most TDPON1 activities of serum and HDLs and HDLs -C levels (except $\mathrm{HDL}_{2}-\mathrm{C}$ ) in all subjects, but not HDLs-C in PGs. The beneficial effects of anaerobic training on SPON1 and $\mathrm{HDL}_{2} \mathrm{AE}$ activities were depend on PON1P. The lack of response of $\mathrm{HDL}_{2}-\mathrm{C}$ to anaerobic exercise will require further research.
\end{abstract}

J Atheroscler Thromb, 2015; 22: 313-326.

Key words: Judo, Paraoxonase-1, PON1-Q192R phenotype, Cholesterol, High-density lipoprotein subgroups, Arylesterase

\section{Introduction}

Coronary artery disease (CAD) is a major cause of death worldwide. Therefore, in addition to the clas-

Address for correspondence: Faruk Turgay, Ege University School of PhysicalEducation and Sport, Department of Sport Health Sciences, 35100 Bornova-Izmir, TURKEY

E-Mail:fturgay@yahoo.com

Received: April 24, 2014

Accepted for publication: October 6, 2014 sical risk factors such as a passive life style, hypertension, diabetes mellitus (DM), and hyperlipidemia ${ }^{1)}$, studies are being conducted on relatively newly identified risk factors, such as blood paraoxonase-1 (PON1; EC.3.1.8.1, aryldialkylphosphatase) enzyme related to high-density lipoprotein $(\mathrm{HDL})^{2,3)}$. The major role of HDL is reverse cholesterol transport from peripheral tissues to the liver. HDL also has antioxidant and antiinflammatory properties, which may protect against $\mathrm{CAD}^{1,4)}$. It has been proposed that the antioxidant 
properties of HDL, which are known to protect against atherosclerosis, are partially derived from PON1 located on $\mathrm{HDL}^{3)}$.

PON1 is an esterase that is widely distributed among various tissues and in serum ${ }^{5}$. PON1 hydrolyzes phenylacetate as well as paraoxon, a poisonous organophosphate compound. The form that uses paraoxon as a substrate is called PON1 and the form that uses phenylacetate as a substrate is called arylesterase $(\mathrm{AE})^{6}$. There is a close physiological association between PON1 and HDL in plasma. HDL facilitates the secretion of PON1 by the liver and stabilizes this enzyme $^{7,8)}$. PON1 is present in HDL subfractions and along with other HDL-associated enzymes, it has a potential role in preventing HDL and low-density lipoprotein (LDL) oxidation ${ }^{2,5,9)}$. It was reported that activity of blood PON $1^{10)}$ and $\mathrm{AE}$ activities of $\mathrm{HDL}$ subgroups (HDL2 and HDL3) ${ }^{11)}$ and PON1 activity and its concentration ${ }^{12)}$ were lower in patients with CAD than the control subjects and low PON1 activity was related to $\mathrm{CAD}^{11,12)}$.

PON1 expression is partly under the control of its genetic variants ${ }^{13}$. When the glutamine at position 192 of a PON1 construct is replaced with arginine, the result is a PON1-Q192R polymorphism. The form with glutamine at position 192 is called a Q genotype and the form with arginine is called an $\mathrm{R}$ genotype. It has been reported that the Q192R polymorphism results in individual variations in the ability to hydrolyze poisonous organophosphate compounds ${ }^{7,}{ }^{13)}$. It has also been reported that people with the Q allele as compared with those with the $\mathrm{R}$ allele have a more antiatherogenic lipid and lipoprotein profile and have a reduced risk of athererosclerosis suggesting a relationship between PON1-Q192R polymorphism and CAD development ${ }^{14,15)}$. Moreover, PON1-Q192R polymorphism has a modifying effect on the effects of exercise on blood lipids and lipoproteins (BLLPs) as well as PON1 enzyme activity ${ }^{16,17)}$. In a study of postmenopausal women, $\mathrm{HDL}_{2}$ and $\mathrm{HDL}_{3} \mathrm{AE}$ activities were better for predicting CAD than the cholesterol levels of HDL and HDLs. Thus, HDL and HDLs AE activity levels could be used as a risk factor for CAD development ${ }^{11)}$. It has been shown that small HDL 3 particles have higher PON1 antioxidant activity than large $\mathrm{HDL}_{2}$ particles ${ }^{18)}$. This protective effect is mediated by HDL and its associated proteins as PON $1{ }^{19)}$. However, it is also known that there is an inverse relationship between HDL-C and the risk of CAD development $^{20)}$.

One study found that low $\mathrm{HDL}_{2}$ levels are more closely associated with $\mathrm{CAD}$ than $\mathrm{HDL}_{3}$ levels ${ }^{21)}$. Another study reported that both $\mathrm{HDL}_{2}-\mathrm{C}$ and
$\mathrm{HDL}_{3}-\mathrm{C}$ levels are related to $\mathrm{CAD}^{22)}$. Thus, a study regarding the effects of anaerobic exercise on PON1 and AE activities, and cholesterol levels of HDLs, and its relationship with PON1-Q192R phenotype (PON1P) may provide important insights for predicting and treating CAD with exercise training. It is known that there are beneficial effects of aerobic exercise on classical CAD risk factors, such as blood lipids and lipoproteins ${ }^{1,17,22)}$, but the effects of anaerobic exercise on recently identified risk factors, such as PON1, are unknown. In addition, the influence of the methods used for measuring PON1 enzyme activities in these types of studies has not been adequately emphasized. For example, paraoxon is a substrate that can distinguish between $\mathrm{Q}$ and $\mathrm{R}$ phenotypes groups. The $\mathrm{R}$ phenotype responds to salt and has a higher enzyme activity against paraoxon. The low activity form $Q$ is inhibited when PON activity is induced with $1 \mathrm{M} \mathrm{NaCl}$, whereas the high activity form $\mathrm{R}$ is not. The phenylacetate substrate cannot distinguish between the $\mathrm{Q}$ and $\mathrm{R}$ groups, because it is hydrolyzed at similar rates with both isoenzymes ${ }^{7)}$. Therefore, there may be different effects of exercise training on these enzyme activities. However, no study has investigated the effects of anaerobic exercise on the three different activities of same PON1 enzyme (TDPON1), including basal PON1, salt-stimulated PON1 (SPON1), and AE activities, of serum, and HDL and its subgroups (HDLs; HDL, HDL2 and HDL3) and on cholesterol levels of HDLs and the possible involvement of PON1P. Thus, in this study, we investigated the effects of anaerobic judo training on the mentioned parameters and its relationship with PON1P in young trained female judoists.

\section{Materials and Methods}

\section{Subjects}

Eighteen Turkish national female judoists (mean age: $17.9 \pm 0.8$ years) participated in this study at the beginning and at the end of 19 weeks prior to their competition season. Their physical characteristics and biochemistry profiles were determined. Critical speeds (CSs) as an indicator of their endurance levels were determined from their maximal 400-m ( $\left.\mathrm{y}_{1}\right)$ and 600-m (y2) running speeds using a modification of the method described by De lucas et al. ${ }^{23)}: \mathrm{m}=\left(\mathrm{y}_{2}-\right.$ $\left.\mathrm{y}_{1}\right) /\left(\mathrm{x}_{2}-\mathrm{x}_{1}\right)$ (x: in seconds). From among 25 female judoists who volunteered to fill out a questionnaire, 18 who met our inclusion criteria were selected for medical examination. These criteria were as follows: (a) $\leq 32$ years of age and a normal menstrual cycle; (b) no illness that may predispose to CAD; (c) no smok- 
ing or alcohol use; (d) not using drugs that could affect lipid, lipoprotein, and antioxidant metabolism; and (e) regular exercise for the last 2 months. These 18 women were assessed for their medical history and underwent physical examination and biochemical testing; they did not meet our exclusion criteria of having a body mass index (BMI) of $\geq 32$, being anemic, or having an active infection. They were instructed not to exercise, not to change their diet, and not to take any medications or supplements for at least $72 \mathrm{~h}$ prior to blood sampling. The aims, possible benefits, tests to be used, and possible risks were explained to the participants and to their parents verbally and in writing, and written consent was obtained from the participants or their parents if they were aged $<18$ years. The ethics committee of the Dokuz Eylül University Medical Faculty approved our study, which was conducted according to ethics committee regulations.

\section{Judo Training}

All subjects were accommodated in the same training camps prior to national and international competitions for about 5 months prior to blood collection. During training camps, they regularly exercised to maintain their physical performance and body mass, as supervised by their coaches. The training intensity was increased in accordance with volume decrements. The last 2 months involved comparatively low-intensity training (approximately 20\%) relative to baseline. The weekly training program included 9 training sessions of a total of $12 \mathrm{~h}$ (6 days/week, $2 \mathrm{~h} /$ day). The details of frequency, volume, and intensity are given below as mean and approximate values. Judo training during these camps covered primarily a repetitive series of short and intense exercises, including various components in a judo session, judo interval training, and technique; situation-specific drills; and Randori, NeWaza, and Tachi Waza (2 sessions of 30 $\mathrm{min}$ each/week). Some additional cardiovascular training, including resistance training (approximately 2 sessions of $80 \mathrm{~min}$ each/week), explosive power training (approximately 2 sessions of $70 \mathrm{~min}$ each/week), stretching (2 sessions of $80 \mathrm{~min}$ each/week), lactate threshold training using running velocities corresponding to $2 \mathrm{mmol} / \mathrm{L}$ and $4 \mathrm{mmol} / \mathrm{L}$ thresholds (2 sessions of $70 \mathrm{~min} /$ week), and fundamental resistance training (power endurance; approximately 2 sessions of $180 \mathrm{sec}$ per workout), were included in these sessions. The participating judoists were undergraduate students at a school of physical education and sports. The participants' daily activities during out of camp schedules were similarly standardized as required by the training camp environment. The participants' daily physical activities in school outside the camps were also similar.

\section{Dietary Details}

Judo is an intermittent sport that includes brief bouts of high intensity, which require energy provided by both aerobic and anaerobic pathways. During very intense training, the participants drank approximately 200-250 $\mathrm{ml}$ of water every 15-20 min during an hourlong training session. If the training time exceeded $1 \mathrm{~h}$, they drank water containing $8 \%$ glucose. The subjects' food intake and fluid consumption during camps were assessed by a staff expert dietician according to the following energy requirements. Nutritional assessment of the daily dietary intake of the judoists was a total of 3000-3500 kcal. It was assessed as daily energy expenditure (kcal/day) with no training: $1800 \mathrm{kcal}$; daily sports activity: $1700 \mathrm{kcal}$; daily energy expenditure (kcal/day): $3350 \mathrm{kcal}$; fat $33.0 \%$; carbohydrate 52\%; and protein $15.0 \%$, with protein intake varying from 1.5 to $1.8 \mathrm{~g}$ per $\mathrm{kg}$ of body mass. The participants were asked to maintain their usual dietary habits during the recording period and to be as accurate as possible in recording the amounts and types of food and fluid consumed. Average daily macro- and micronutrient intakes were calculated from a 7-day food record using a dietary survey similar to that reported previously ${ }^{24)}$. In addition, the participants in this study also performed lifestyle activities such as jogging and swimming.

\section{Blood Sampling and Analysis}

Venous blood samples were obtained after an overnight fasting period (not during the participants menstrual periods) in $8-\mathrm{mL}$ serum vacuum tubes at 9:00 am. The blood samples were allowed to clot at $25^{\circ} \mathrm{C}$ for $30 \mathrm{~min}$ and then centrifuged at $2000 \mathrm{~g}$ for $10 \mathrm{~min}$. Then, the serum samples were separated and maintained at $-70^{\circ} \mathrm{C}$ until the biochemical assays were performed as a single batch. Biochemical variables were determined within 1 month after obtaining the serum samples.

\section{Assays for HDL-C, $\mathrm{HDL}_{2}-\mathrm{C}$, and $\mathrm{HDL}_{3}-\mathrm{C}$ (HDLs-C)}

Supernatants with $\mathrm{HDL}$ and $\mathrm{HDL}_{3}$ were obtained using polyethylene glycol (MW: 20,000; Merck) according to previously described methods ${ }^{25}$ ) and cholesterol, PON1, SPON1, and AE contents of serum and HDLs (HDL and its subgroups) were analyzed by following methods. HDL2 contents were estimated by calculating the difference between HDL and $\mathrm{HDL}_{3}$. Serum total cholesterol (TC), triglycerides (TGs), HDL, and its subgroups 's cholesterol levels 
( $\mathrm{HDL}_{2}-\mathrm{C}$ and $\left.\mathrm{HDL}_{3}-\mathrm{C}\right)$ were quantified using the standardized enzymatic methods using commercial kits (Dialab Gmbh, Austria) and an autoanalyzer (Moduler DP, Roche Diagnostics, Japan). LDL-C was determined as described by Friedewald et $a{ }^{26}{ }^{26}$.

\section{Measurement of PON1 and SPON1 Activities}

PON1 and SPON1 activities of serum, HDL, and $\mathrm{HDL}_{3}$ subgroup supernatants were determined with an autoanalyzer (Moduler DP, Roche Diagnostics, Japan) using paraoxon (Sigma Chemical Co, St. Louis, USA) as the substrate.

\section{PON1 Activity}

PON1 and SPON1 activity ${ }^{7)}$ was measured after the paraoxon hydrolysis reaction in terms of p-nitrophenol and diethylphosphate production catalyzed by the enzyme. PON1 activity was determined from the initial velocity of p-nitrophenol production (after subtracting spontaneous paraoxon hydrolysis) at $412 \mathrm{~nm}$ and $37^{\circ} \mathrm{C}$. The assay mixture included $1.0 \mathrm{mM}$ paraoxon, $1.0 \mathrm{mM} \mathrm{CaCl}_{2}$, and serum in $50 \mathrm{mM}$ Tris- $\mathrm{HCl}$ buffer ( $\mathrm{pH}$ 7.4). One unit of PON1 activity was defined 1 micro mol of $\mathrm{p}$-nitrophenol produced per minute. The precision of PON1 analysis after 10 runs with a serum pool was $115.1 \pm 1.2 \mathrm{U} / \mathrm{L}$ [constant of variation $(\mathrm{CV})=1.07 \%$, with blanks of $0.9 \pm 1.5 \mathrm{U} / \mathrm{L}$. Linearity analysis using $1 / 4,1 / 2,3 / 4,3 / 2$, and $2 / 1$ dilutions of a 339-U/L sample gave a regression equation of $y=338.9 x-8.3\left(R^{2}=0.999\right)$ that was linear up to $675 \mathrm{U} / \mathrm{L}$.

\section{SPON1 Activity}

Serum SPON1 activity was determined according to a previously described method ${ }^{27}$. With this method, $1.0 \mathrm{M} \mathrm{NaCl}$ was added to the mixture included $1.0 \mathrm{mM}$ paraoxon, $1.0 \mathrm{mM} \mathrm{CaCl}_{2}$ in a 50 $\mathrm{mM}$ glycine buffer ( $\mathrm{pH}$ 10.5). One unit of PON activity was defined as $1.0 \mu \mathrm{mol}$ of p-nitrophenol produced per minute. This was performed using the same conditions and methods as used for PON1 activity. The precision of basal SPON1 analysis after 10 runs with a serum pool was $331.7 \pm 3.5 \mathrm{U} / \mathrm{L}(\mathrm{CV}=1.06 \%)$, with blanks of $0.7 \pm 0.7 \mathrm{U} / \mathrm{L}$. Linearity analysis using $1 / 4,1 / 2$, and $3 / 4$ dilutions of a $895-\mathrm{U} / \mathrm{L}$ sample gave a linear regression equation of $y=904.1 x-14.0\left(R^{2}=\right.$ 0.999). The PON1 and SPON1 contents of HDL 2 were estimated by the difference between HDL and $\mathrm{HDL}_{3}$.

\section{AE Activity}

$\mathrm{AE}$ activities of serum, $\mathrm{HDL}$, and $\mathrm{HDL}_{3}$ supernatants were determined spectrophotometrically (Shi- madzu UV160A, Japan) using phenylacetate as the substrate (Merck-Schuchardt, Germany) by recording phenol absorbance at $270 \mathrm{~nm}$ at $37^{\circ} \mathrm{C}$. AE activity was determined according to previously described methods ${ }^{6,7)} 3.0 \mathrm{ml}$ assay mixture contained $1.0 \mathrm{mM}$ phenylacetate, $0.9 \mathrm{mM} \mathrm{CaCl}_{2}$, and $5 \mu \mathrm{l}$ of serum in 9.0 $\mathrm{mM}$ Tris- $\mathrm{HCl}$ buffer ( $\mathrm{pH} 8.0$ ). One unit of AE hydrolyses $1.0 \mathrm{mmol}$ of the substrate per minute, with the results presented as kilo units (KU/L) of serum. Serum dilutions of 1:3-1:4 were used. The AE activity of $\mathrm{HDL}_{2}$ was estimated by calculating the difference between the AE activities of HDL and HDL3. The precision of basal $\mathrm{AE}$ analysis after 10 runs with a serum pool was $50.1 \pm 2.7 \mathrm{KU} / \mathrm{L}(\mathrm{CV}=5.4 \%)$. Linearity analysis using $1 / 5,1 / 3$, and $1 / 2$ dilutions of a 71.3$\mathrm{KU} / \mathrm{L}$ sample gave good linear regression results $\left(\mathrm{R}^{2}=0.998\right)$. The interassay CV for AE was $<7.0 \%$.

\section{Statistical Analysis}

Data were analyzed using SPSS 20.0 for Windows (Release 22, Chicago, IL, USA). The data for overall subjects (OS) and the phenotype groups (PGs) were normally distributed. To statistically compare changes in PON1, SPON1, and AE enzyme activities and BLLPs after exercise training with respect to basal values, paired Students' $t$-tests were used with Bonferroni corrections for multiple comparisons. Unpaired $t$-tests were used to compare the mean results of continuous variables in the PGs according to PON1 phenotyping. Multivariate ANOVA (MANOVA) for repeated measures was used to test for possible interactions with regard to PON1 activity levels. Correlations between variables were determined using Pearson correlation analysis. $P$ value of $\leq 0.05$ was considered significant. The $\mathrm{G}^{*}$ Power 3.0 statistical power analysis program $^{28)}$ was used to test for the size effects for any differences that were found.

\section{Results}

\section{PON1-Q192R Phenotyping}

PON1-Q192R phenotype (PON1P) distributions in $\mathrm{OS}$ were determined using both paraoxon and phenylacetate as substrates, according to the method of Eckerson at al. ${ }^{7}$. To determine the phenotype of a given participant as QQ (homozygous low activity), QR (heterozygous moderate activity), or RR (homozygous high activity), the ratio of SPON1 to AE activities was used to assign phenotypes to individuals. After a frequency analysis, those with a SPON1 to AE ratio of $\leq 2.90$ were considered as the QQ phenotype group (QG; $n=9$ ), those with ratios between 2.90 and 5.07 were considered as the QR group $(n=6)$, and 
Table 1. Physical and physiological characteristics of overall subjects and phenotype groups Pre-T and Post-T

\begin{tabular}{lcccccc}
\hline & $\begin{array}{c}\text { Age } \\
\text { (years })\end{array}$ & $\begin{array}{c}\text { Height } \\
(\mathrm{cm})\end{array}$ & $\begin{array}{c}\mathrm{BM} \\
(\mathrm{kg})\end{array}$ & $\begin{array}{c}\mathrm{BMI} \\
\left(\mathrm{kg} / \mathrm{m}^{2}\right)\end{array}$ & $\begin{array}{c}\mathrm{CS} \\
(\mathrm{km} / \mathrm{h})\end{array}$ & $\begin{array}{c}\text { SE } \\
\text { (years) }\end{array}$ \\
\hline Overall $(n=18)$ & & & & & & \\
Pre-T & $17.9 \pm 0.8$ & $162.8 \pm 7.0$ & $65.6 \pm 15.1$ & $24.6 \pm 4.8$ & $13.1 \pm 1.6$ & $7.1 \pm 2.4$ \\
Post-T & $17.9 \pm 0.8$ & $162.9 \pm 7.1$ & $64.9 \pm 13.0$ & $24.5 \pm 4.0$ & $12.7 \pm 1.4$ & $7.1 \pm 2.4$ \\
Difference & $P>0.05$ & $P>0.05$ & $P>0.05$ & $P>0.05$ & $P>0.05$ & $P>0.05$ \\
QG ( $n=9)$ & & & & & & \\
Pre-T & $18.0 \pm 0.9$ & $164.6 \pm 7.2$ & $65.3 \pm 11.9$ & $24.0 \pm 3.4$ & $13.8 \pm 1.6$ & $6.8 \pm 2.9$ \\
Post-T & $18.0 \pm 0.9$ & $164.6 \pm 7.2$ & $65.8 \pm 11.7$ & $24.3 \pm 0.8$ & $13.1 \pm 0.7$ & $6.8 \pm 2.9$ \\
Difference & $P>0.05$ & $P>0.05$ & $P>0.05$ & $P>0.05$ & $P>0.05$ & $P>0.05$ \\
RG (n=9) & & & & & & \\
Pre-T & $17.9 \pm 0.8$ & $161.0 \pm 6.7$ & $65.8 \pm 18.5$ & $25.2 \pm 3.5$ & $12.33 \pm 1.5$ & $7.3 \pm 1.9$ \\
Post-T & $17.9 \pm 0.8$ & $161.0 \pm 6.7$ & $63.9 \pm 14.8$ & $24.7 \pm 4.7$ & $12.30 \pm 1.8$ & $7.3 \pm 1.9$ \\
Difference & $P>0.05$ & $P>0.05$ & $P>0.05$ & $P>0.05$ & $P>0.05$ & $P>0.05$ \\
\hline
\end{tabular}

Values are presented as means \pm SDs. Pre-T: Pre-training, Post-T: Post-training, QG: QQ homozygous phenotype group, RG: R carriers phenotype group, CS: Critical speed, BM: body mass, BMI: Body mass index; SE: Sport experience. $P$-values were derived from comparisons between the results obtained before and after training.

those with a ratio of $\geq 5.08(n=3)$ were considered as the RR phenotype group. Thus, $9(50.0 \%)$ participants were classified as QQ, $6(33.3 \%)$ as QR, and 3 $(16.6 \%)$ as RR. Because the number of participants was low, the RR and QR groups together were defined as the $\mathrm{R}$ carrier group (RG; $n=9)$. The $\mathrm{QG}$ frequency in this sampling group paralleled that for Caucasian cohorts $^{29)}$. The frequency distribution of our participants showed a trimodal distribution. The frequency distribution for the QQ and RR phenotype groups confirmed to a Hardy-Weinberg distribution ${ }^{7)}$.

\section{Subjects' Physical and Physiological Characteristics}

The physical and physiological characteristics of the judoists in this study before (pre-training; Pre-T) and after (post-training; Post-T) training are shown in Table 1. CS was calculated on the basis of maximal $400-\mathrm{m}$ and 600-m running times. Regardless of PON1P, there were no significant differences Pre-T and Post- $\mathrm{T}$ with regard to the maximal results for both $400-\mathrm{m}(81.6 \pm 11.9$ versus $80.9 \pm 11.7 \mathrm{~s})$ and $600-\mathrm{m}$ $(137.69 \pm 17.30$ versus $138.23 \pm 17.25$ s) running times. In addition, there were no significant differences Pre-T and Post- $T$ for the results of the other variables shown in Table $\mathbf{1}$ among the different PGs. Thus, there were no significant differences among the PGs for these subjects' physical and physiological characteristics Pre-T and Post-T.

\section{BLLP Profiles}

BLLP profiles Pre-T and Post-T are shown in Table 2, both with and without considering PON1P.

\section{Effects of Exercise Training}

When PON1P were not considered, only serum $\mathrm{HDL}-\mathrm{C}$ and $\mathrm{HDL}_{3}-\mathrm{C}$ levels were significantly increased compared with their basal levels Post-T (Table 2). TC, LDL-C, HDL $2-C$, and TG levels did not change significantly. However, TG levels did decrease Post-T (11.2\%), although this was not significant.

When PON1P were considered, although HDL-C and $\mathrm{HDL}_{3}-\mathrm{C}$ levels did not change significantly in the PGs Post-T, the effect sizes of the differences in these variables were found in the $R G, \mathrm{~d}_{1}=1.23$ and $\mathrm{d}_{2}=0.66$, which were determined using the $G^{*}$ Power program ${ }^{28)}$. This trend for an increase was similar to that in OS. There were no significant differences between the PGs for basal BLLP levels, except TGs (QG > RG) (Table 2).

\section{PON1, SPON1 and AE Activities}

The results for PON1, SPON1 and AE activities of serum, and HDLs Pre-T and Post-T are shown in Tables 3 and 4, respectively, both with and without considering PON1P.

\section{Effects of Exercise Training}

When PON1P were not considered, PON1, SPON1, and AE activities of serum; PON1 and SPON1 activities of HDLs; and HDL AE activity increased significantly compared with their basal levels Post-T (Tables 3 and 4).

When PON1P were considered, as expected, PON1 and SPON1 activities of serum, and HDLs were significantly higher for $R$ carriers (RG) than for 
Table 2. Serum lipid and lipoprotein profiles for overall subjects and phenotype groups Pre-T and Post-T

\begin{tabular}{|c|c|c|c|c|c|c|}
\hline & $\begin{array}{c}\mathrm{TC} \\
(\mathrm{mM})\end{array}$ & $\begin{array}{l}\text { TG } \\
(\mathrm{mM})\end{array}$ & $\begin{array}{l}\text { LDL-C } \\
(\mathrm{mM})\end{array}$ & $\begin{array}{l}\text { HDL-C } \\
(\mathrm{mM})\end{array}$ & $\begin{array}{c}\mathrm{HDL}_{2}-\mathrm{C} \\
(\mathrm{mM})\end{array}$ & $\begin{array}{l}\mathrm{HDL}_{3}-\mathrm{C} \\
(\mathrm{mM})\end{array}$ \\
\hline \multicolumn{7}{|l|}{ Overall $(n=18)$} \\
\hline Pre-T & $4.58 \pm 1.01$ & $0.89 \pm 0.27$ & $3.00 \pm 0.86$ & $1.16 \pm 0.24$ & $0.30 \pm 0.12$ & $0.85 \pm 0.18$ \\
\hline Post-T & $4.47 \pm 0.82$ & $0.79 \pm 0.26$ & $2.76 \pm 0.76$ & $1.35 \pm 0.24$ & $0.37 \pm 0.15$ & $0.98 \pm 0.17$ \\
\hline Difference & $P>0.05$ & $P>0.05$ & $P>0.05$ & $P<0.05$ & $P>0.05$ & $P<0.05$ \\
\hline \multicolumn{7}{|l|}{ QG $(n=9)$} \\
\hline Pre-T & $4.88 \pm 0.83$ & $1.03 \pm 0.25$ & $3.17 \pm 0.74$ & $1.24 \pm 0.23$ & $0.33 \pm 0.11$ & $0.98 \pm 0.18$ \\
\hline Post-T & $4.77 \pm 0.84$ & $0.75 \pm 0.23$ & $3.03 \pm 0.83$ & $1.37 \pm 0.28$ & $0.34 \pm 0.19$ & $1.02 \pm 0.17$ \\
\hline Difference & $P>0.05$ & $P>0.05$ & $P>0.05$ & $P>0.05$ & $P>0.05$ & $P>0.05$ \\
\hline \multicolumn{7}{|l|}{$\mathrm{RG}(n=9)$} \\
\hline Pre-T & $4.24 \pm 1.12$ & $0.77 \pm 0.23$ & $2.82 \pm 0.98$ & $1.07 \pm 0.22$ & $0.28 \pm 0.13$ & $0.79 \pm 0.18$ \\
\hline Post-T & $4.17 \pm 0.71$ & $0.75 \pm 0.29$ & $2.48 \pm 0.59$ & $1.34 \pm 0.22$ & $0.39 \pm 0.11$ & $0.94 \pm 0.16$ \\
\hline Difference & $P>0.05$ & $P>0.05$ & $P>0.05$ & $P>0.05$ & $P>0.05$ & $P>0.05$ \\
\hline \multicolumn{7}{|l|}{ Pre-T QG-RG } \\
\hline Difference & $P>0.05$ & $P<0.05$ & $P>0.05$ & $P>0.05$ & $P>0.05$ & $P>0.05$ \\
\hline
\end{tabular}

Values are presented as means \pm SDs. Pre-T: Pre-training, Post-T: Post-training, QG: QQ homozygous phenotype group, RG: R carriers phenotype group. TC: Total cholesterol, HDL-C: High-density lipoprotein cholesterol, HDL2-C: High-density lipoprotein 2 cholesterol, HDL3-C: Highdensity lipoprotein 3 cholesterol, LDL-C: low-density lipoprotein cholesterol, TG: Triglycerides. $P$-values were derived from comparisons between the results obtained before and after training.

QG Pre-T and Post-T. There were no differences among the PGs for basal AE activities of serum and HDLs (Tables 3 and 4.). These results showed that PON1P was related to on PON1 activities, but it had no effect on blood $\mathrm{AE}$ activities, which confirmed the phenotyping method used in this study ${ }^{7)}$.

When PON1P were considered, Post- $T$ in the QG, serum PON1, HDL PON1, and HDL2 PON1 activities were significantly increased, whereas serum and HDLs SPON1 activities (except HDL SPON1) did not change significantly. In the RG, $\mathrm{HDL}_{2}$ and $\mathrm{HDL}_{3} \mathrm{PON}_{1}$ activities did not significantly change, whereas serum PON1, SPON1, HDL PON1, and HDLs SPON1 activities increased significantly (Table 3).

With regard to the PGs, AE activities of serum and HDLs did not change significantly, except for an increase in $\mathrm{HDL}_{2} \mathrm{AE}$ in the RG (Table 4). Significant interactions were found among training effects and PON1P for serum SPON1 $(P=0.010)$ and HDL 2 AE $(P=0.05)$ activities.

\section{Correlations Among Variables}

As expected, for all subjects, serum PON1 and SPON1 activities were significantly correlated $(r=0.992, p=0.000)$. No significant correlations were found between serum PON1 and SPON1 activities with $\mathrm{AE}$ and between serum PON1, SPON1, and AE activities with CS, HDL-C, and TG basal values.
However, significant correlations were found between CS and HDL PON1 $(r=0.516, P<0.05)$, HDL 2 PON1 $(r=0.563, P<0.05)$, HDL SPON1 $(r=0.542, P<0.05)$, and $\mathrm{HDL}_{3}$ SPON1 $(r=0.553$, $P<0.05)$ results only Post-T in OS.

\section{Discussion}

In this study, for the first time, we assessed the effects of anaerobic training on three different activities of the PON1 enzyme of HDLs and its relationship with PON1P in humans. Our main findings were that anaerobic judo training resulted in significant increases in most TDPON1 activities of serum and HDLs (except AE activity) and cholesterol levels of HDLs (except HDL $2-C$ ). These effects were independent of PON1P. Changes in SPON1 and HDL 2 AE activities by anaerobic training were depend on PON1P, but not for basal BLLP levels.

\section{Training Effects on BLLP Profiles and Possible Mechanisms}

Although anaerobic judo training significantly increased cholesterol levels of HDLs (except $\mathrm{HDL}_{2}-\mathrm{C}$ ) in OS, BLLP levels did not change significantly Post$T$ in PGs. However, the effect sizes for the differences in HDL-C and $\mathrm{HDL}_{3}-\mathrm{C}$ levels in the $\mathrm{RG}$ were $\mathrm{d}_{1}=1.23$ and $\mathrm{d}_{2}=0.66$, respectively. The trend for an increase in these two variables was similar to the trend 
Table 3. PON1 and SPON1 activities of serum, HDL, and HDL subgroups for overall subjects and phenotype groups pre-T and post-T

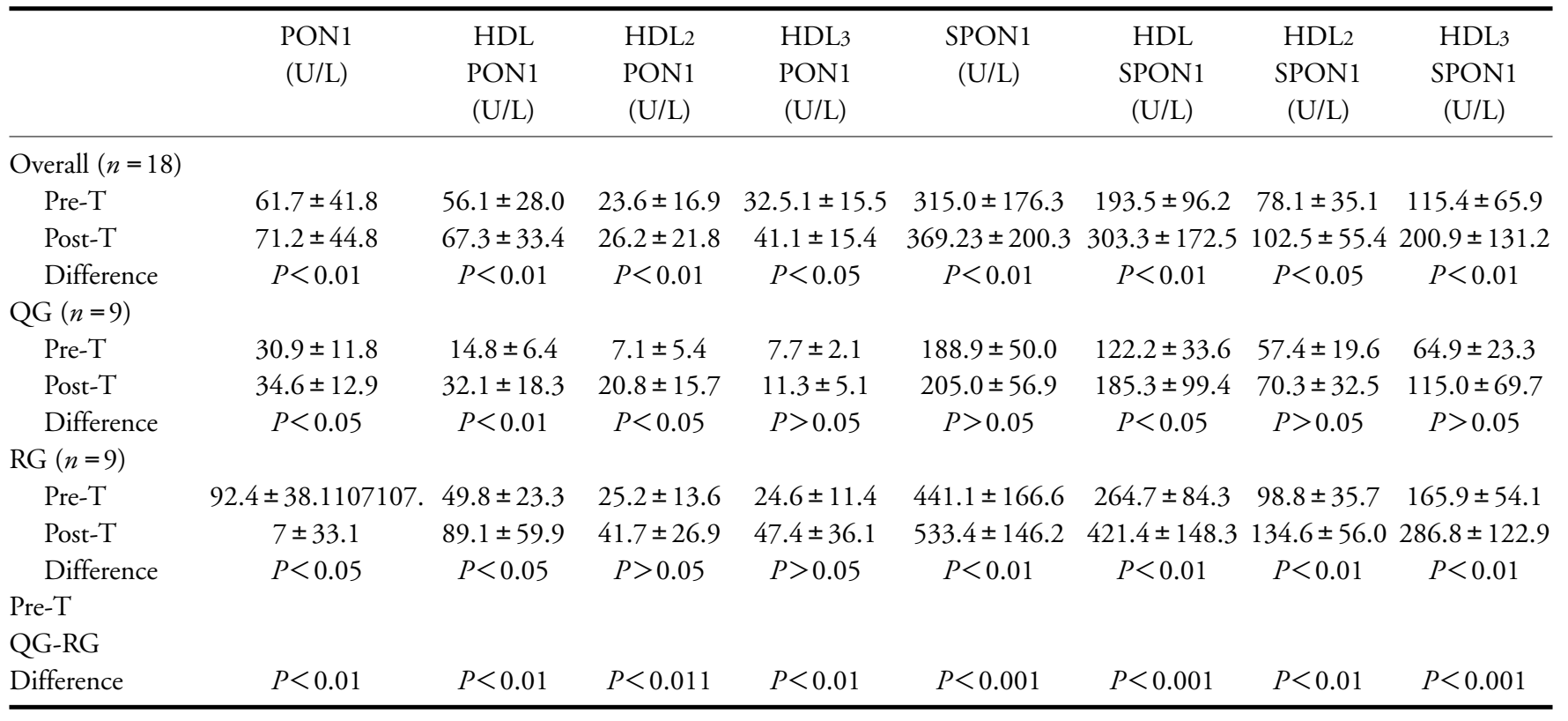

Values are presented as means \pm SDs. Pre-T: Pre-training, Post-T: Post-training, QG: QQ homozygous phenotype group, RG: R carriers phenotype group, PON1: PON1 activity, HDL PON1: HDL PON1 activity, HDL2 PON1: HDL2 PON1 activity, HDL3 PON1: HDL3 PON1 activity, SPON1: Salt-stimulated PON1 activity, HDL SPON1: HDL salt-stimulated PON1 activity, HDL2 SPON1: HDL2 salt-stimulated PON1 activity, HDL3 SPON1: HDL3 salt-stimulated PON1 activity. $P$-values were derived from comparisons between the results obtained before and after training.

Table 4. AE activities of serum, HDL, and HDL subgroups for overall subjects and phenotype groups Pre-T and Post-T

\begin{tabular}{lcccc}
\hline & $\begin{array}{c}\mathrm{AE} \\
(\mathrm{KU} / \mathrm{L})\end{array}$ & $\begin{array}{c}\mathrm{HDL} \text { AE } \\
(\mathrm{KU} / \mathrm{L})\end{array}$ & $\begin{array}{c}\text { HDL } 2 \mathrm{AE} \\
(\mathrm{KU} / \mathrm{L})\end{array}$ & $\begin{array}{c}\text { HDL } 3 \text { AE } \\
(\mathrm{KU} / \mathrm{L})\end{array}$ \\
\hline Overall $(n=18)$ & & & & \\
Pre-T & $60.9 \pm 25.7$ & $57.5 \pm 12.0$ & $15.7 \pm 7.0$ & $41.8 \pm 11.8$ \\
Post-T & $71.4 \pm 25.2$ & $67.1 \pm 15.3$ & $21.0 \pm 8.6$ & $46.2 \pm 14.5$ \\
Difference & $P<0.05$ & $P<0.05$ & $P>0.05$ & $P>0.05$ \\
QG $(n=9)$ & & & & \\
Pre-T & $69.9 \pm 27.0$ & $61.3 \pm 13.9$ & $17.6 \pm 6.9$ & $43.7 \pm 15.1$ \\
Post-T & $78.6 \pm 32.2$ & $70.3 \pm 17.9$ & $17.9 \pm 6.0$ & $52.5 \pm 15.7$ \\
Difference & $P>0.05$ & $P>0.05$ & $P>0.05$ & $P>0.05$ \\
RG $(n=9)$ & & & & \\
Pre-T & $51.8 \pm 22.3$ & $53.7 \pm 9.1$ & $13.8 \pm 7.0$ & $39.9 \pm 7.9$ \\
Post-T & $64.2 \pm 14.2$ & $63.9 \pm 12.3$ & $24.0 \pm 10.0$ & $39.9 \pm 10.7$ \\
Difference & $P>0.05$ & $P>0.05$ & $P<0.05$ & $P>0.05$ \\
Pre-T QG-RG & & & & $P>0.05$ \\
Difference & $P>0.05$ & $P>0.05$ & $P>0.05$ & \\
\hline
\end{tabular}

Values are presented as means \pm SDs. Pre-T: Pre-training, Post-T: Post-training, QG: QQ homozygous phenotype group, RG: R carriers phenotype group, AE: Arylesterase activity, HDL AE: HDL arylesterase activity, HDL 2 AE: HDL2 arylesterase activity, HDL3 AE: HDL 3 arylesterase activity, KU/L: Kilo units /Liter. P-values were derived from comparisons between the results obtained before and after training. 
in OS. In addition, PON1P was not related to the effects of training on BLLP levels. Therefore, the main reason for these differences between the PGs and OS may have been the low number of participants in PGs. Thus, the increases in HDL-C and $\mathrm{HDL}_{3}-\mathrm{C}$ levels were deemed to be worth consideration in PGs, but independently from PON1P.

In general, physical activity is beneficial for preventing cardiovascular disease because of its effects on the classical risk factors such as BLLP levels. Physical activity results in reduced plasma TG levels and increased HDL levels ${ }^{1)}$, as well as HDL-associated enzymes, such as PON ${ }^{16)}$. Bailey et al. ${ }^{30)}$ found decreases in serum TC, HDL-C, and LDL-C levels in trained subjects who performed at $70 \%-85 \%$ of their maximum heart rates for 4 weeks, which is different from the findings of the present study. In contrast, 3 months of moderate aerobic exercise did not improve BLLP levels in females ${ }^{31)}$.

The differences in BLLP levels due to exercise primarily depend on exercise intensity, duration, and frequency, as well as lifestyle factors such as diet, sex, smoking, and alcohol consumption ${ }^{1,17,32,33)}$. Therefore, our study results could have been affected by these factors. It has been reported that the potential effects of exercise training on lipoprotein subclass distributions, enzymes, and apoproteins often occur together with changes in the diet and body composition and that these changes may be responsible for all or part of the lipoprotein changes attributed to aerobic exercise ${ }^{1)}$. Unlike other studies, in the present study, the significant increases in HDLs-C (except $\mathrm{HDL}_{2}-\mathrm{C}$ ) occurred without any change in body composition, CS, and TC and LDL-C levels, despite judo training being primarily anaerobic in nature.

It has previously been shown that changes in TC, LDL-C ${ }^{34)}$, and HDLs-C levels ${ }^{35)}$ due to training are inversely related to their basal levels. The participants in the present study had normal BLLP and body composition profiles. Therefore, the main reason for no change in body fatness in the judoists in the present study may also have been a ceiling effect; that is, it may not be possible in young women whose baseline levels are already low ${ }^{36)}$. Furthermore, because trained judoists should maintain their body fitness, they have to pay attention to their diet. Thus, the factors noted above may have been involved in the improvements in HDLs-C (except $\left.\mathrm{HDL}_{2}-\mathrm{C}\right)$, without any change in body composition and TC and LDL-C levels in the present study.

In contrast to the results of the present study, $\mathrm{HDL}_{2}-\mathrm{C}$ levels were shown to increase in basketball and wrestling athletes, sports that are primarily anaer- obic like judo, whereas $\mathrm{HDL}_{3}$ levels increased in all groups and controls because of acute maximal endurance exercise ${ }^{37)}$. Therefore, it would be expected that anaerobic exercise training like judo would also induce chronic modifications and intermolecular redistributions of HDL-C and subfractions. It is also possible that an increased flux of lipids to HDL-C molecules may result from the regulatory actions of lipoprotein lipase (LPL), and thus, HDLs-C levels could change ${ }^{37)}$.

In support of our proposition, in another study on the acute effects of a resistance exercise like judo and intensive exercise, it was found that HDL-C levels and lecithin-cholesterol acyltransferase (LCAT) activity were increased; these enzymes increase HDL-C levels ${ }^{38)}$. It was also found that changes in the clearance rates of exogenous fat were directly related to changes in HDLs-C levels ${ }^{39)}$. In the present study, although TG levels were not significantly reduced, TG levels did decrease by $11.2 \%$ Post-T. This decrease in TG levels may have reflected an increase in the TG clearance rate ${ }^{17}$. Our findings support our proposition that judo training may increase HDLs-C levels because of an increase in the TG clearance rate. Thus, the results of the present study show that anaerobic (Judo) training can improve HDLs-C levels (except $\mathrm{HDL}_{2}-\mathrm{C}$ ), without any significant changes in performance (CS) or physical changes. Furthermore, it was shown that lifestyle activities such as jogging or swimming can improve BLLP levels, including HDL-C levels ${ }^{40)}$.

The participants in the present study also performed lifestyle activities such as jogging and swimming. Thus, there may also have been an additive effect of these lifestyle activities, as well as other factors for improvements in HDLs-C levels. However, in this study, $\mathrm{HDL}_{2}-\mathrm{C}$ levels did not change significantly in both the different PGs and OS Post-T, which was independent of PON1P. The reason why HDL 2 levels did not change by judo training is unknown.

It was previously reported that high-intensity aerobic training results in improvements in HDL-C levels, whereas for resistance and combined exercises, the results were inconsistent ${ }^{41)}$. In a meta-analysis of 19 randomized controlled trials, aerobic exercise resulted in increased $\mathrm{HDL}_{2}-\mathrm{C}$ levels in adults, with a statistically significant increase of only approximately $11 \%$ for $\mathrm{HDL}_{2}-\mathrm{C}^{42)}$. These factors may also affect the results. The possible explanations for this are that $\mathrm{HDL}_{2}-\mathrm{C}$ may be more insensitive to exercise stress than $\mathrm{HDL}_{3}-\mathrm{C}$ or the anaerobic nature of judo training may limit or not affect HDL metabolism and the major enzymes that regulate HDL compositions, including LPL and LCAT activities. 


\section{Effects of PON1P on BLLP Levels}

A previous study reported an association between PON1-192 polymorphism and BLLP levels, and those who were homozygous (QQ) for the low-activity allele of PON1 had less atherogenic lipoprotein profiles ${ }^{15)}$. In studies of middle-aged men in the $\mathrm{R}$ carrier group $(\mathrm{RR}+\mathrm{QR})^{17)}$ and in nonmenopausal women in the RR homozygous group ${ }^{43)}$, the effects of physical activity on BLLPs and basal BBLLP levels ${ }^{44)}$ were modified by PON1 192 polymorhism; in contrast, some studies, including a study of a Turkish population, did not show any association between PON1 192 polymorhism and lipoprotein profiles, similar to the results of the present study ${ }^{45,46)}$. The differences between these studies may be due primarily to PON1 192 polymorhism $^{17,47)}$ and other factors noted above ${ }^{32,33)}$. In the present study, which is the first study of a healthy Turkish population, no relationship was found between PON1P and basal BLLP levels, and PON1P was not related to the effects of training on BLLP levels.

Therefore, the results of the present study show that anaerobic (Judo) training can also improve HDLs-C levels (except HDL $2-C$ ) without any significant changes in performance or physical characteristics and independently of PON1P.

\section{Training Effects on Blood TDPON1 Activities and PON1P Involvement}

One of the best known antiinflammatory and antioxidant functions of HDL is its inhibition of LDL oxidation $^{5,27)}$. This function of HDL may be due to the chemical composition of HDL, presence of liposoluble antioxidants associated with these particles, and enzymes such as platelet-activating factor acetylhydrolase (PAF-AH), LCAT, and PON1 ${ }^{2,5)}$.

A previous study demonstrated a significant decrease in PON1 concentrations and $\mathrm{AE}$ and PON1 activities in CAD patients compared with that in control subjects ${ }^{12)}$. It has also been reported that CAD is associated with oxidative stress and that antioxidants may increase PON1 activity, whereas oxidative stress may inhibit PON1 activity ${ }^{2,16)}$. Thus, determining PON1 activity in CAD patients and healthy persons is important. In a previous study, PON1 activities and HDL-C levels were positively correlated in control subjects and CAD patients ${ }^{4,8)}$. In the present study, no significant correlations were found between PON1, SPON1, and AE activities and HDL-C levels and CS results. Thus, the changes in TDPON1 activities were independent of HDL-C and physical performance levels.

In one study ${ }^{48)}$, serum $\mathrm{AE}$ activity increased by
$17 \%$ after aerobic cardiac therapy exercise, in subjects with CAD similarly to the present study results ${ }^{48)}$, although different exercises were applied in these two studies. In another study of men and women, PON1 activities in the physical activity group were higher than those in the control group and smokers. However, inactive smokers had significantly lower PON1 activity levels than inactive non-smokers ${ }^{32}$.

These findings show that physical activity with both aerobic and anaerobic (as judo) exercises improves $\mathrm{AE}$ and PON1 activities. In another study, after maximal exercise (ME), an increase in PON1 activities was found; however, no changes in AE activity were found in trained rugby players. PON1 changes during $\mathrm{ME}$ were dependent on age, body composition, and training experience as different from the present study, although the influence of PON1P on PON1 changes at $\mathrm{ME}$ was uncertain ${ }^{49)}$.

In the present study, PON1P was not related to the effects of exercise training on AE activity. In addition, AE activity was not related to PON1 and SPON1 activities. These findings show that the increases in AE activity are independent of PON1P and support that the finding $\mathrm{AE}$ activity does not depend on PON1-Q192R polymorphism. It has been reported that $\mathrm{AE}$ activity can be used as a marker for the PON1 protein ${ }^{4)}$. Thus, in this study, the increases in $\mathrm{AE}$ activity may have been the result of an increase in PON1 enzyme protein levels in OS. However, significant any change in AE activities of serum or HDLs (except an increase in $\mathrm{HDL}_{2} \mathrm{AE}$ activity in the RG) did not occur in PGs Post-T. The reasons for this are unknown and difficult to explain on the basis of these findings. However, in the present study, a weak interaction was found between PON1P and HDL 2 AE activities in PGs $(P=0.05)$.

We showed that basal serum AE activities and the differences in $\mathrm{AE}$ activity were independent of PON1P. However, serum PON1 and SPON1 activities increased concomitantly with HDLs PON1 activities, whereas serum $\mathrm{AE}$ and $\mathrm{HDL} \mathrm{AE}$ activities increased without any significant increases in $\mathrm{HDL}_{2}$ $\mathrm{AE}$ and $\mathrm{HDL}_{3} \mathrm{AE}$ activities and independently of these variables in OS. These data show that the activities of HDLs can also vary independently. However, although AE activity is not associated with any known polymorphism, it is possible that $\mathrm{HDL}_{2} \mathrm{AE}$ activity could be affected by PON1P in the different PGs. This is possible because it has been reported that linkage disequilibrium with other functional mutations in the PON gene cluster or at another gene on chromosome $7 \mathrm{q}$ can cause interactions and that these interactions may produce phenotype differences ${ }^{16,50)}$. There- 
fore, the increase in $\mathrm{HDL}_{2} \mathrm{AE}$ activity in the $\mathrm{RG}$ may have been a result of the interactions between gene and environmental factors, such as exercise. However, more studies are needed for a complete description of this state.

In another study that supported our view, Thomas et al. ${ }^{16)}$ did not find a significant effect of acute and chronic aerobic exercise on SPON1 activity. However, it was found that exercise had a significant effect on SPON1 activity when PON1 192 polymorphism was considered. No significant relationship was found between physical activity and PON1 activity in those aged 18-75 years, different from the observations of the present study ${ }^{33)}$. These findings show that PON1 192 polymorphism can affect the study results.

It has been shown that with regard to resistance to oxidative stress, the $\mathrm{Q}$ group had better protection than the $\mathrm{R}$ group ${ }^{16)}$. Therefore, according to this hypothesis, it is possible for these two phenotypes to vary with regard to adapting to oxidative stress caused by exercise. With regard to the negative effect seen in the $\mathrm{R}$ group, two hypotheses are possible ${ }^{16)}$. First, people with the $\mathrm{R}$ phenotype may be much more sensitive to a possible inhibition of PON1 activity caused by oxidative stress resulting from exercise. Second, there may be miscommunication between PON1-192 polymorphism and another polymorphism in the PON1 gene promoter area or another area may alter PON1 synthesis or activity.

In contrast to the results of Thomas et al. ${ }^{16)}$, in the present study, the increases in both SPON1 and $\mathrm{HDL}_{2} \mathrm{AE}$ activities in the RG were depend on PON1P. That is, serum SPON1 and HDL 2 AE activities increased only in the RG after the training but not in the QG (Tables 3 and 4). In Turkish and Japanese populations, it was found that PON1 192 RR alleles have greater protective effects than QQ alleles against oxidative stress in individuals with type $2 \mathrm{DM}$ and non-diabetic control subjects ${ }^{47,51)}$. Therefore, the improvements in SPON1 and HDL 2 AE in the RG but not in the QG in the present study could also be explained by the reasons noted in the study by Thomas et al. ${ }^{16)}$. The results regarding PON1 and $\mathrm{HDL}_{2} \mathrm{AE}$ in the present study are the first to be reported in the literature and in a Turkish population.

Cakmak A. et al. ${ }^{52)}$ found that PON1 activities, were significantly higher in trained adolescent athletes than in controls. PON1 activities were remarkably higher in adolescents involved in wrestling (which is anaerobic in nature) at baseline than in those who were sedentary. In addition, anaerobic wrestling exercise for a healthy life reduces DNA damage and enhances antioxidant variables ${ }^{53)}$. However, we did not determine the oxidative stress status in the present study. Wrestling sports are very similar to judo; therefore, a high antioxidant defense capacity may also have derived from chronic judo training in the present study. In addition, Koury et al. ${ }^{54)}$ showed that the antioxidant system could improve in elite judo athletes. Therefore, the increases in PON1 activities may have reflected improvements in antioxidant capacity Post-T.

In general, regular physical activity causes a repeated increase in the release of free radicals as a result of each exercise session, which hypothetically acts as a transcription inducer for endogenous antioxidant genes, particularly PON $1^{55)}$. Thus, judo training may have also improved antioxidant capacity in the subjects of the present study. In addition, we found relationships between CS and HDL PON1, HDL2 PON1, HDL SPON1, and HDL 3 SPON1 results in all subjects only Post-T. These results show that CS had beneficial effects on PON1 activities (except AE activity) due to training without quantitative improvements in CS. CS reflects some aerobic enzymes's potential capacities and can predict the fitness status of athletes ${ }^{23)}$. Thus, CS is a marker of aerobic endurance capacity. Although CS did not quantitatively change Post-T, some metabolic changes, such as the release or production of PON1, may have been triggered during training. Therefore, the relationships found in the present study may reflect developments in PON1 activities. Some studies showed that there were changes in PON1 activity or antioxidant capacity of HDLs in the absence of changes in BLLP levels and antioxidant capacity ${ }^{56,57)}$.

These study results support our proposition that exercise can change PON1 release and its activity by internal developments in organisms without any quantitative changes in other factors, such as physical composition, performance, and BLLP levels in welltrained athletes Post-T. In addition, it has been reported that PON1 levels and activity could be modified by lifestyle determinants, such as smoking, antioxidant vitamins, alcohol consumption, and $\operatorname{sex}^{32,33,48)}$. Tomas et al. ${ }^{16)}$ used salt-stimulated PON1, Chemitus et al. ${ }^{11)}$ evaluated both PON and AE activities, and other studies determined PON1 activity (by paraoxon). There were differences among the results of the present study and those of previous studies. If we had used only basal PON1 activity in the present study, then it appears that our results would be very different. These results show that the measurement methods used for PON1 enzyme activities may have resulted in the differences among other studies as in the present study. 


\section{Effects of Exercise on HDLs and Clinical Significance}

Because PON1 has been suggested to be responsible for the antioxidant properties of HDL, PON1 and $\mathrm{AE}$ activities, particularly $\mathrm{AE}$ activity, may reflect HDL dysfunctionality, despite no differences in HDL levels between patients and controls ${ }^{58)}$. And blood AE activity was higher in sportsmen ${ }^{59)}$. PON1 has been found in the $\mathrm{HDL}_{2}$ species of $\mathrm{HDL}$ in particles enriched in triacylglycerols ${ }^{60)}$. Because PON1 tends to bind to larger-sized species of HDL both in vivo and in vitro, but PON1 activity and HDL's size may decrease in certain diseases as type $2 \mathrm{DM}^{60)}$. However, one study ${ }^{61)}$ reported that in both diabetic and nondiabetic groups, small dense $\mathrm{HDL}_{3}$ particles exerted more potent protection against LDL oxidation than large light $\mathrm{HDL}_{2}$ particles and that the antioxidative dysfunctionality of small dense $\mathrm{HDL}_{3}$ particles in type 2 DM was closely associated with elevated oxidative stress and with the degree of glycemia and triglyceridemia.

Previous studies have reported a significant reduction in PON1 activity and HDL2-C in persons with $\mathrm{CAD}^{10,21)}$. In addition, $\mathrm{HDL}_{2}$ and $\mathrm{HDL}_{3} \mathrm{AE}$ activities in women with $\mathrm{CAD}$ were lower than those in the control group, and these variables were better for predicting CAD than the cholesterol levels of HDLs; thus, HDLs AE activities levels could be used as a risk factor for $\mathrm{CAD}^{11)}$. The causal relationship between blood HDL-C levels and CAD has been explained by the involvement of these lipoproteins in reverse cholesterol transport, as well as by other potentially antiatherogenic properties of HDL, such as its antioxidative enzymes and other effects ${ }^{1}$.

Because the major role of $\mathrm{HDL}_{2}-\mathrm{C}$ appears to be as a final receptor in the reverse cholesterol transport process, increases in $\mathrm{HDL}_{2}-\mathrm{C}$ as a result of aerobic exercise occurred independently of changes in physical characteristics, and statistically significant increases were found in $\mathrm{HDL}_{2}-\mathrm{C}$ but not important in HDL$\mathrm{C}^{42)}$. In addition, of the two major HDL-C subfractions, $\mathrm{HDL}_{2}-\mathrm{C}$ may provide greater protection against $\mathrm{CAD}$ than $\mathrm{HDL}_{3}-\mathrm{C}^{62)}$. Therefore, no increase in HDL-C in the clinical setting may not be indicative of a lack of cardioprotection within this lipoprotein group $^{42)}$. Therefore, it may be important to determine PON1 and AE activities and the cholesterol contents of HDLs to control HDL functions.

In the present study, $\mathrm{HDL}_{2}-\mathrm{C}_{\text {levels }}$ in $\mathrm{OS}$ and $\mathrm{HDL}_{2} \mathrm{AE}$ activities in the QG did not change Post-T. Despite their similarities, the turnover of the $\mathrm{Q}$ and $\mathrm{R}$ isozymes of PON1 differ with paraoxon, but are similar with phenylacetate. Therefore, in addition to PON1P, one other possible model that could explain these differences in $\mathrm{HDL}_{2} \mathrm{AE}$ activities in the $\mathrm{RG}$ is that the rate of phenylacetate hydrolysis is far greater (about 1000-fold) than the rate of paraoxon hydrolysis $^{7)}$. Furthermore, the favorable improvements in $\mathrm{HDL}_{2}-\mathrm{C}$ levels and $\mathrm{HDL}_{2} \mathrm{AE}$ activities may have been due to a different threshold of training as well as other factors in OS or the QG. Thus, further research is needed to provide an adequate description for these phenomena.

The absence of favorable changes in HDLs AE activities of serum and cholesterol levels of $\mathrm{HDL}_{2}$ may be a disadvantage for some individuals in the QG after a physical activity or any therapy. Therefore, the results of this study should provide insights on these issues.

\section{Limitations}

Based on our literature search, this is the first study to show that anaerobic training has effects on three different activities of the same PON1 enzyme and the cholesterol contents of HDLs and its relationship with PON1P. However, this study was limited because it was conducted with a small number of athletes including only young females and did not involve genotyping or determination of the oxidative stress status. However, we believe that our study results contribute considerably to current knowledge through the measurements used for various PON1 activities of serum, and HDLs and for emphasizing the effects of PON1P and PON1 activity measurement methods on this type of study. Our data also reveal that for predicting the risk of CHD and preparing a rehabilitation program that also includes exercise, it may be necessary to monitor cholesterol contents as well as SPON1, PON1 and AE enzyme activities of HDL and its subgroups and PON1P.

\section{Conclusions}

Anaerobic training resulted in improvements in most TDPON1 activities of serum and HDLs and HDLs-C levels in OS, but not in HDLs-C in PGs. The effects of training on SPON1 and HDL 2 AE activities were depend on PON1P. HDL $2-C$ in all of our subjects, and AE activity in most PGs may have been insensitive to anaerobic exercise. The different measurement methods of PON I enzyme activity may affect the study results.

\section{Acknowledgments}

We express our sincere gratitude to Özden Açikkol and her athletes. 


\section{Conflicts of Interest}

The authors have no conflicts of interest to disclose and have no financial relationships with any organization that sponsored this research. We did not receive any funding for this study.

\section{References}

1) Superko HR: Exercise training, serum lipids, and lipoprotein particles. is there a change threshold? Med Sci Sports Exerc, 1991; 23: 677-685

2) Mackness MI, Arrol S, Durrington PN: Paraoxonase prevents accumulation of lipoperoxides in low-density lipoprotein. FEBS Lett, 1991; 286: 152-154

3) Mackness MI, Arrol S, Abbott CA, Durrington PN: Protection of low-density lipoprotein against oxidative modification by high-density lipoprotein associated paraoxonase. Atherosclerosis, 1993; 104: 129-135

4) Costa LG, Vitalone A, Cole TB, Furlong CE: Modulation of paraoxonase (PON1) activity. Biochemical pharmacology, 2005; 69(4): 541-550

5) Aviram M, Rosenblat M, Bisgaier CL, Newton RS, Primo-Parmo SL, LaDu BN: Paraoxonase inhibits high density lipoprotein oxidation and preserves its functions. JClin Inves, 1998; 101(8): 1581-1590

6) Gan KN, Smolen A, Eckerson HW, La DU BN: Purification of human Paraoxonase/arylesterase: evidence for one esterase catalyzing both activities. Drug Metab Disp, 1991; 19: $100-106$

7) Eckerson HW, Wyte CM, La Du BN: The human serum paraoxonase/arylesterase polymorphism. Am J Hum Genet, 1983; 35: 1126-1138

8) Deakin S, Leviev I, Gomaraschi M, Calabresi L, Franceschini G, James RW: Enzymatically active paraoxonase-1 is located at the external membrane of producing cells and released by a high affinity, saturable, desorption mechanism. J Biol Chem, 2002; 277: 4301-4308

9) Bergmeier C, Siekmeier R, Gross W: Distribution spectrum of paraoxonase activity in HDL fractions. Clin Chem, 2004; 50(12): 2309-2315

10) Ayub A, Mackness MI, Arrol S, Mackness B, Patel J, Durrington PN: Serum paraoxonase after myocardial infarction. Arterioscler Thromb Vasc Biol, 1999; 19: 330335

11) Chemnitius JM, Winkel H, Meyer I, Schirrmacher K, Armstrong VW, Kreuzer H, Zech R: Age related decrease of high density lipoproteins (HDL) in women after menopause. Quantification of HDL with genetically determined HDL arylesterase in women with healthy coronary vessels and in women with angiographically verified coronary heart disease. Med Klin, 1998; 93(3): 137-145

12) Mackness B, Davies GK, Turkie W, Lee E, Roberts DH, Hill E, Roberts C, Durrington PN, Mackness MI: Paraoxonase status in coronary heart disease: are activity and concentration more important than genotype? Arterioscler Thromb Vasc Biol, 2001; 21(9): 1451-1457

13) Rojas-García AE, Solís-Heredia MJ, Pina-Guzman B, Vega L, Lopez-Carrillo L, Quintanilla-Vega B: Genetic polymorphisms and activity of PON1 in a Mexican population. Toxicol Appl Pharmacol, 2005; 205: 282-289

14) Serrato M, Marian AJ: A variant of a human paraoxonase arylesterase (HUMPONA) gene is a risk factor for coronary artery disease. J Clin Invest, 1995; 96: 3005-3008

15) Hegele RA, Brunt JH, Connelly PW: A polymorphism of the paraoxonase gene associated with variation in plasma lipoproteins in a genetic isolate. Arterioscler Thromb Vasc Biol, 1995; 15(1): 89-95

16) Tomás M, Elosua R, Senti M, Molina L, Vila J, Anglada R, Fitó M, Covas MI, Marrugat J: Paraoxonase1-192 polymorphism modulates the effects of regular and acute exercise on paraoxonase1 activity. J Lipid Res, 2002; 43(5): 713-720

17) Senti M, Aubó C, Elosua R, Sala J, Tomás M, Marrugat J: Effects of physical activity on lipid levels in a populationbased sample of men with and without the Arg192 variant of the human paraoxonase gene. Genet Epidemiol, 2000; 18(3): 276-286

18) Kontush A, Chantepie S, Chapman MJ: Small, dense HDL particles exert potent protection of atherogenic LDL against oxidative stress. Arterioscler Thromb Vasc Biol, 2003; 23: 1881-1888

19) Efrat M, Aviram M: Paraoxonase 1 Interactions with HDL, Antioxidants and Macrophages Regulate Atherogenesis A Protective Role for HDL Phospholipids. Adv Exp Med Biol, 2010; 153-166

20) Genest J, Marcil M, Denis M, Yu L: High density lipoproteins in health and in disease [Review]. J Investig Med, 1999; 47: 31-42

21) Salonen JT, Salonen R, Sepptien K, Rauramaa R, Tuomilehto J: HDL, HDL2, and HDL3 subfractions, and the risk of acute myocardial infarction. Cimdadon, 1991; 84: 129-139

22) Superko HR, Pendyala L, Williams PT, Momary KM, King SB 3rd, Garrett BC: High- density lipoprotein subclasses and their relationship to cardiovascular disease. J Clin Lipidol, 2012; Nov-Dec; 6(6): 496-523

23) De Lucas RD, Dittrich N, Junior RB, de Souza KM, Guglielmo LG: Is the critical running speed related to the intermittent maximal lactate steady state? J Sports Sci Med Mar, 2012; 1; 11(1): 89-94

24) Degoutte F, Jouanel P, Filaire E: Energy demands during a judo match and recovery. Br J Sports Med, 2003; 37: 245-249

25) Kostner GM, Molinari E, Pichler P: Evaluation of a new HDL2/HDL3 quantitation method based on precipitation with polyethylene glycol. Clin Chim Acta, 1985; 48: 139-147

26) Friedewald WT, Levy RI, Fredrickson DS: Estimation of the concentration of low-density lipoprotein cholesterol in plasma, without use of the preparative ultracentrifuge. Clin Chem, 1972; 18: 499-502

27) Eckerson HW, Romson J, Wyte C, La Du BN: The human serum paraoxonase polymorphism: identification of phenotypes by their response to salts. Am J Hum Genet, 1983; 35(2): 214-227

28) Faul F, Erdfelder E, Lang AG, Buchner A: G*Power 3: a flexible statistical power analysis program for the social, behavioral, and biomedical sciences. Behav Res Methods, 
2007; May; 39(2): 175-191

29) Aydin M, Gencer M, Cetinkaya Y, Ozkok E, Ozbek Z, Kilic G, Orken C, Tireli H, Kara I: PONI 55/192 polymorphism, oxidative stress, type, prognosis and severity of stroke. IUBMB Life, 2006; Mar; 58(3): 165-172

30) Bailey DM, Davies B, Baker J: Training in hypoxia: modulation of metabolic and cardiovascular risk factors in men. Med Sci Sports Exerc, 2000; 32: 1058-1066

31) Brownell KD, Bachorik PS, Ayerle RS: Changes in plasma lipid and lipoprotein levels in men and women after a program of moderate exercise. Circulation, 1982; 65: 477484

32) Senti M, Tomas M, Annglada R, Elosua R, Marrugat J, Covas MI, Fitó M: Interrelationship of smoking, paraoxonase activity, and leisure time physical activity: a population- based study. Eur J Intern Med, 2003; 14: 178-184

33) Ferré N, Camps J, Fernández-Ballart J, Arija V, Murphy MM, Ceruelo S, Biarnés E, Vilella E, Tous M, Joven J: Regulation of serum paraoxonase activity by genetic, nutritional, and lifestyle factors in the general population. Clin Chem, 2003; 49(9): 1491-1497

34) Angelopoulos TJ, Sivo SA, Kyriazis GA, Caplan JD, Zoeller RF, Lowndes J, Seip RL, Thompson PD: Eur J Appl Physiol. Do age and baseline LDL cholesterol levels determine the effect of regular exercise on plasma lipoprotein cholesterol and apolipoprotein B levels? Eur J Appl Physiol, 2007; 101(5): 621-628

35) Leon AS, Gaskill SE, Rice T, Bergeron J, Gagnon J, Rao DC, Skinner JS, Wilmore JH, Bouchard C: Variability in the response of HDL cholesterol to exercise training in the HERITAGE Family Study. Int J Sports Med, 2002; Jan; 23(1): 1-9

36) Poehlman ET, Dvorak RV, DeNino WF, Brochu M, Ades PA: Effects of resistance training and endurance training on insulin sensitivity in nonobese, young women: a controlled randomized trial. J Clin Endocrinol Metab, 2000; Jul; 85(7): 2463-2468

37) Sgouraki E, Tsopanakis A, Tsopanakis C: Acute exercise: response of HDL-C, LDL-C lipoproteins and HDL-C subfractions levels in selected sport disciplines. J Sports Med Phys Fitness, 2001; Sep; 41(3): 386-391

38) Wallace MB, Moffatt RJ, Haymes EM, Green NR: Acute effects of resistance exercise on parameters of lipoprotein metabolism. Metabolism, 1991; 2: 199-204

39) Sady SP, Thompson PD, Cullinane EVI. Kantor VIA, Domoyala E, Herbert PN: Prolonged exercise augments plasma tnglyceride clearance. JAMA, 1986; 256; 25522555

40) Hata Y, Nakajima K: Life-style and serum lipids and lipoproteins. J Atheroscler Thromb, 2000; 7(4): 177-197

41) Tambalis K, Panagiotakos DB, Kavouras SA, Sidossis LS: Responses of Blood Lipids to Aerobic, Resistance, and Combined Aerobic With Resistance Exercise Training: A Systematic Review of Current Evidence. Angiology, 2009; 60 (5): 614-632

42) Kelley GA, Kelley KS: Aerobic exercise and HDL2-C: A meta- analysis of randomized controlled trials. Atherosclerosis, 2006; January; 184(1): 207-215

43) Manresa JM, Tomás M, Ribes E, Pi-Figueras M, Aguilera A, Sentí M, Marrugat J: Paraoxonase 1gene 192 polymor- phism, physical activity and lipoprotein in women. Med Clin (Barc) Spanish, 2004; 22: 126-129

44) Sentí M, Tomás M, Marrugat J, Elosua R; REGICOR Investigators: Paraoxonase1-192 polymorphism modulates the nonfatal myocardial infarction risk associated with decreased HDLs. Arterioscler Thromb Vasc Biol, 2001; Mar; 21(3): 415-420

45) Sanghera DK, Saha N, Aston CE, Kamboh MI: Genetic polymorphism of paraoxonase and risk of coronary heart disease. Arterioscler Thromb Vasc Biol, 1997; 17(6): 1067-1073

46) Agachan B, Yilmaz H, Isbir T, Akoglu E: Paraoxonase 192 Polymorphism and its Relationship to Serum Lipids in Turkish Renal Transplant Recipients. Transplant Proc, 2004; 36(5): 1385-1386

47) Agachan B, Yilmaz H, Ergen HA, Karaali ZE, Isbir T: Paraoxonase (PON1) 55 and 192 polymorphism and its effects to oxidant-antioxidant system in turkish patients with type 2 diabetes mellitus. Physiol Res, 2005; 54(3): 287-293

48) Goldhammer E, Ben-Sira D, Zaid G, Biniamini Y, Maor I, Lanir A, Sagiv M: Paraoxonase activity following exercise-based cardiac rehabilitation program. J Cardiopulm Rehabil Prev, 2007; 27: 151-154

49) Otocka-Kmiecik A, Bortnik K, Szkudlarek U, Nowak D, Orłowska-Majdak M: Effect of exercise on plasma paraoxonase 1 activity in rugby players: dependance on training experience. Redox Rep, 2013; 18(3): 113-119

50) Leus FR, Zwart M, Kastelein JJ, Voorbij HA: PON2 gene variants are associated with clinical manifestations of cardiovascular disease in familial hypercholesterolemia patients. Atherosclerosis, 2001; Feb 15; 154(3): 641-649

51) Kotani K, Tsuzaki K, Sakane N: Paraoxonase-1 gene Q192R polymorphism and reactive oxygen metabolites. J Int Med Res, 2012; 40(4): 1513-1518

52) Cakmak A, Zeyrek D, Atas A, Erel O: Paraoxonase activity in athletic adolescents. Pediatr Exerc Sci, 2010; Feb; 22(1): 93-104

53) Hamurcu Z, Saritas N, Baskol G, Akpinar N: Effect of wrestling exercise on oxidative DNA damage, nitric oxide level and paraoxonase activity in adolescent boys. PediatrExerc Sci, 2010; Feb; 22(1): 60-68

54) Koury JC, de Oliveira CF, Portella ES, Oliveira AV Jr, Donangelo CM: Effect of the period of resting in elite judo athletes: hematological indices and copper/zincdependent antioxidant capacity. Biol Trace Elem Res, 2005; Dec; 107(3): 201-211

55) Sun Y, Oberley LW: Redox regulation of transcriptional activators. Free Radic Biol Med, 1996; 21: 335-348

56) Romani R, De Medio GE, di Tullio S, Lapalombella R, Pirisinu I, Margonato V, Veicsteinas A, Marini M, Rosi G: Modulation of paraoxonase 1 and 3 expression after moderate exercise training in the rat. J Lipid Res, 2009; 50: 2036-2045

57) Iborra RT, Ribeiro IC, Neves MQ, Charf AM, Lottenberg SA, Negrão CE, Nakandakare ER, Passarelli M: Aerobic exercise training improves the role of high- density lipoprotein antioxidant and reduces plasma lipid peroxidation in type 2 diabetes mellitus. Scand J Med Sci Sports, Dec 2008; 18(6): 742-750 
58) Gaillard T, Parthasarathy S, Osei K: HDL dysfunctionality (paraoxonase) is worse in nondiabetic, postmenopausal African American than in white women. Diabetes Care, 2011; 3(4): e19. doi: 10.2337/dc10-1189

59) Brites F, Zago V, Verona J, Muzzio ML, Wikinski R, Schreier L: HDL capacity to inhibit LDL oxidation in welltrained triathletes. Life Sci, 2006; 78: 3074-3081

60) Deakin SP, James RW: Genetic and environmental factors modulating serum concentrations and activities of the antioxidant enzyme paraoxonase-1. Clin Sci (Lond), Nov
2004; 107(5): 435-447

61) Nobécourt E, Jacqueminet $S$, Hansel B, Chantepie $S$, Grimaldi A, Chapman MJ, Kontush A: Defective antioxidative activity of small dense HDL3 particles in type 2 diabetes: relationship to elevated oxidative stress and hyperglicaemia. Diabetologia, 2005; 48: 529-538

62) Morgan J, Carey C, Lincoff A, Capuzzi D: High-density lipoprotein subfractions and risk of coronary artery disease. Curr Atheroscler Rep, 2004; 6: 359-365 